\section{Deficiency of a Leukocyte Surface Glycoprotein (LFA-1) in Two Patients with Mo1 Deficiency \\ Effects of Cell Activation on Mo1/LFA-1 Surface Expression in Normal and Deficient Leukocytes}

M. Amin Amaout, Hergen Spits, Cox Terhorst, Jane Pitt, and Robert F. Todd III

Divisions of Nephrology and Cell Biology, Children's Hospital, Boston, Massachusetts 02115; Division of Tumor Immunology and Laboratory of Molecular Immunology, Dana Farber Cancer Institute, Harvard Medical School, Boston, Massachusetts 02115; The Netherlands Cancer Institute, Amsterdam; and the Division of Infectious Disease, Columbia College of Physicians and Surgeons, New York 10032 bstract. Mol, a phagocyte surface glycoprotein heterodimer, is involved in a number of phagocyte adhesion functions such as binding and ingestion of serum-opsonized particles, zymosan-induced degranulation, and superoxide generation. Deficiency of this antigen in humans has been associated with increased susceptibility to recurrent bacterial infections. The beta subunit of Mol is shared by another surface glycoprotein named LFA-1, which is involved in lymphocyte proliferation, cytolytic $\mathrm{T}$ cell, and natural killing activities. Two unrelated patients with Mol deficiency were found to be deficient in LFA-1 as well as in the common beta subunit. Investigation of lymphocyte functions in these two patients revealed normal mixed leukocyte culturegenerated cytolytic $T$ cell and natural killing activities and significantly reduced proliferative response to phytohemagglutinin. LFA-1-deficient cells also proliferated in response to soluble antigen and different alloantigens. These responses were partially blocked by anti-LFA-1

Parts of this work were presented at the American Society for Clinical Investigation, Washington, DC, May 1984, and at the Federation of American Societies for Experimental Biology meetings in St. Louis, MO, June 1984.

Dr Arnaout is an Established Investigator of the American Heart Association. Address correspondence to Dr. Arnaout, Children's Hospital, Boston, MA 02115.

Received for publication 1 December 1983 and in revised form 31 May 1984.

J. Clin. Invest.

(C) The American Society for Clinical Investigation, Inc. $0021-9738 / 84 / 10 / 1291 / 10 \$ 1.00$

Volume 74, October 1984, 1291-1300 antibody. Whereas LFA-1 was undetectable by immunofluorescence and immunoprecipitation on the patients' resting $T$ cells, significantly reduced ( $\sim 5 \%$ of normal) but detectable amounts of the heterodimeric LFA-1 antigen were found on mitogen and alloantigen-activated $T$ cells. On granulocytes, Mol surface expression was also dependent on the state of cellular activation. The amount of surface Mol present on resting normal granulocytes increased by 3-10-fold following exposure to stimuli that induced degranulation, suggesting the presence of a major intracellular pool for this antigen. Analysis of subcellular fractions from granulocytes showed that intracellular Mol is located primarily in the specific granule fraction. Activated granulocytes had little or no increase in their surface expression of LFA1 antigen. Deficient granulocytes had significantly increased numbers of Mol antigen expressed on the surface following stimulation with calcium ionophore (1 $\mu \mathrm{M})$. However, the amount expressed continued to be significantly reduced compared with normal cells. Quantitation of surface Mol on granulocytes exposed to calcium ionophore $(1 \mu \mathrm{M})$ showed that both parents in one family but only the mother in the other family had significantly reduced levels of Mol, suggesting heterogeneity in the inheritance of this disorder. Whereas LFA-1 deficiency on lymphocytes was associated with normal alloantigen-induced cytolytic $T$ cell and natural killing activities in these two patients, functions which were in part dependent on small amounts of detectable LFA-1 antigen, the Mol deficiency state led to significant defects in phagocyte adhesion functions. Hence, the clinical symptoms associated with this combined defi- 
ciency state reflect a more profound phagocyte than lymphocyte disorder.

\section{Introduction}

Adherence between cells of the immune system, such as lymphocytes, monocytes, or granulocytes, and other cells or particles is an important step in the complex series of events that mediate such biologic functions as cell-mediated killing, phagocytosis, chemotaxis, degranulation, and superoxide anion production. The use of monoclonal antibodies to cell surface structures has identified two distinct surface molecules (Mol and LFA-1) which appear to be involved in some of these adherence reactions (1-3). Mol, a structure closely associated or identical with the human complement $\mathrm{C} 3 \mathrm{bi}$ receptor, consists of two noncovalently linked glycoproteins of 155 (alpha subunit) and $94 \mathrm{kD}$ (beta subunit) $(1,4,5)$. It is present on human monocytes, granulocytes, and null cells $(5,6)$. LFA-1, an antigen associated with lymphocyte functions, is also a heterodimer (alpha subunit, $177 \mathrm{kD}$; beta subunit, $94 \mathrm{kD}$ ) and is present on $\mathrm{T}$ and $\mathrm{B}$ cells, monocytes, and granulocytes $(2,3)$. Previous studies in the mouse $(3,7)$ and human systems $(8$; Borst, J., and C. Terhorst, unpublished data) demonstrated that the beta subunits of LFA-1 and Mol (or the related epitopes, Mac-1 and OKM1) are highly homologous or identical. Monoclonal antibodies directed to Mol on phagocytes or LFA-1 on lymphocytes inhibit the rate of phagocytosis of opsonized particles or lymphocyte-mediated cytolysis, respectively $(1,2)$, a finding that is consistent with their function as adherence molecules.

Recently, two unrelated patients with recurrent bacterial infections and Mol deficiency were described (9-12). The patients' phagocytes were deficient in both the alpha and beta subunits of Mol and had impaired phagocytosis of opsonized particles as well as defective zymosan-induced degranulation and superoxide generation. In this report, we present data showing that leukocytes from these two patients are also deficient in LFA-1. We also determined the effects of LFA-1 deficiency on lymphocyte proliferation and cytotoxic activities. The amount of LFA-1 and Mol expressed on the surface of lymphocytes and granulocytes, respectively, was critically dependent on the state of activation of these cells. Detectable but significantly reduced amounts of LFA-1 antigen with normal mobility on polyacrylamide gels were seen on activated but not resting $T$ cells from these patients. Activated granulocytes from the parents of one patient but only the mother of the other patient expressed significantly reduced amounts of Mol, suggesting heterogeneity in the mode of inheritance of this disease.

\section{Methods}

Cell separation. Human peripheral blood leukocytes (PBL) and nonadherent cells containing predominantly $T$ lymphocytes were isolated as detailed elsewhere (5). Granulocytes were purified at $4^{\circ} \mathrm{C}$ on cushions of Ficol-Hypaque (specific gravity 1095) followed by hypotonic lysis of the contaminating erythrocytes (modified from reference 13). Monocytes were obtained by adherence of PBL to petri dishes (5), or by centrifugation of PBL on a Percoll gradient (14). B cell lines Laz 509, 388, Namalva, and Daudi were kindly provided by Dr. $H$. Lazarus, Dana Farber Cancer Institute.

Monoclonal antibodies. Mouse ascites containing monoclonal antibodies L1, L5, or L11 (all of the IgG1 noncomplement fixing subclass) directed against a lymphocyte function-associated antigen (LFA-1) (15) as well as antibodies to I-2 (Ia) (16), Mol, Mo2, Mo5, and Mo6 $(5,6)$ were obtained as described. L1, L5, or L11 antibodies were not directly cytotoxic to $T$ cells (15). Monoclonal antibodies to T3, T4, T8, and TA-1 were generously provided by Dr. S. F. Schlossman (17) (Dana Farber Cancer Institute) and Dr. T. LeBien (University of Minnesota) (18).

Other reagents. The following reagents were purchased: calcium ionophore A23187 (Eli Lilly and Co., Indianapolis, IN), phorbol myristate acetate (Consolidated Midland Chemical Co., Brewster, NY), concanavalin A (Con A)' (Calbiochem-Behring Corp., La Jolla, CA), phytohemagglutinin (PHA) (Wellcome Reagents Ltd., Beckenham, England), C5a desarg (Upjohn Co., Kalamazoo, MI), dimethyl sulfoxide and $f$-Met-Leu-Phe (Sigma Chemical Co., St. Louis, MO), and Percoll (Pharmacia Fine Chemicals, Piscataway, NJ).

Immunofluorescence and immunoprecipitation studies. Indirect immunofluorescence was performed by exposing test cells to saturating amounts of monoclonal antibodies followed by staining with a fluorescein-conjugated goat anti-mouse immunoglobulin reagent as previously described (5). Immunofluorescence intensity as a quantitative measure of relative antigen expression was analyzed on an Ortho cytofluorograph FC 200/4800 A (Ortho Instruments, Westwood, MA) using a logarithmic amplifier. The channel number (log scale) representing the peak fluorescence intensity of 10,000 cells exposed to either experimental or control antibodies was determined. Linear fluorescence intensity channels were computed from a logarithmic-linear calibration curve (19). Immunoprecipitation from ${ }^{125}$ I-surface labeled granulocytes or PHA-generated lymphoblasts using monoclonal antibodies to LFA-1 or anti-Mol were performed and analyzed exactly as described elsewhere (1).

Quantitation of cell surface Mol antigen was also done using a direct binding assay (1). Briefly, $75 \mu \mathrm{l}$ of granulocytes $\left(3 \times 10^{7} / \mathrm{ml}\right.$ for untreated cells, or $1 \times 10^{7} / \mathrm{ml}$ for calcium ionophore-treated cells) were incubated with increasing amounts of ${ }^{125} \mathrm{I}-\mathrm{Fab}$ anti-Mol in the presence or absence of a 100 -fold molar excess of unlabeled antibody in a total volume of $100 \mu$ l of phosphate-buffered saline (PBS), pH 7.4, containing $0.5 \%$ human serum albumin. Incubation was done for $40 \mathrm{~min}$ at $0^{\circ} \mathrm{C}$, after which granulocytes were separated from unbound antibody on phthalate oil cushions and the specific binding calculated (1).

Lymphocyte proliferation and cytotoxicity assays. Proliferation and cytolytic T lymphocyte (CTL) assays were performed as previously described (modified from Reference 17). Briefly, PBL $\left(2 \times 10^{5}\right)$ from patient or control individuals were cultured in medium containing tetanus toxoid (TT) 1:800 final dilution (State Biological Labs, Department of Public Health, Jamaica Plain, MA), PHA (0.125-0.5 $\mu \mathrm{g} /$ $\mathrm{ml}$ final concentration), or Con A $(6.25-62.5 \mu \mathrm{g} / \mathrm{ml})$ in a total volume of $200 \mu \mathrm{l}$ of RPMI 1640 (Microbiological Associates, Walkersville,

1. Abbreviations used in this paper: Con A, concanavalin A; CTL, cytolytic T lymphocyte; MLR, mixed leukocyte reaction; PHA, phytohemagglutinin; TT, tetanus toxoid. 
MD) containing $10 \%$ heat-inactivated human AB serum. After $4 \mathrm{~d}$ (PHA or Con A) or $5 \mathrm{~d}$ (TT), cells were pulsed with $0.8 \mu \mathrm{Ci}$ [3H]thymidine $(1.9 \mathrm{Ci} / \mathrm{mM}$ specific activity, Schwartz Mann, Spring Valley, NY) and were harvested $16 \mathrm{~h}$ later on a Mash 2 apparatus (Microbiologic Associates). $\left[{ }^{3} \mathrm{H}\right]$ Thymidine incorporation was measured in Packard scintillation counter (Packard Instruments Co., Downers Grove, IL). To determine the effect of the IgGI anti-LFA-1 on these proliferative responses, the monoclonal antibody or anti-Mo6, a control antibody of an identical subclass, was introduced at the start of the proliferation assay in 1:120 or 1:256 final concentration. Mixed leukocyte reaction (MLR) of patient or control cells in response to four different B cell lines Laz 509, Laz 388, Namalva, or Daudi was determined in an identical fashion except that $1.6 \times 10^{3}-5 \times 10^{4}$ of these mitomycin C-treated cells were added per well instead of TT, PHA, or Con A, and cultures were harvested on day 6 after a $16 \mathrm{~h}\left[{ }^{3} \mathrm{H}\right]$ thymidine pulse To measure the effect of PHA or MLR stimulation on LFA-1 surface expression, lymphoblasts were harvested on day 5 (PHA) or day 6 (MLR) and indirect immunofluorescence or immunoprecipitation from ${ }^{125}$ I surface-labeled cells using anti-LFA-1 monoclonal antibodies were performed and compared with that of resting cells.

For the CTL assay, target B cell lines were selected that elicited a proliferative response in the MLR assay. To generate CTL, $2 \times 10^{5}$ PBL from patient or control individuals were cultured with $2.5 \times 10^{4}$ mitomycin C-treated Laz 388 or Laz 509 B cells in U-bottom microtiter wells $(200 \mu \mathrm{l})$ for $6 \mathrm{~d}$. To measure alloantigen-specific cytolytic activity, MLR-generated effector cells were harvested and incubated in microtiter plates at various effector to target cell ratios with the corresponding target cells that were previously labeled with sodium 51 chromate $\left({ }^{51} \mathrm{Cr}\right)(292 \mathrm{Ci} / \mathrm{mM})(\mathrm{New}$ England Nuclear, Boston, MA). The plates were centrifuged at $500 \mathrm{~g}$ for $5 \mathrm{~min}$, and subsequently incubated for 4 $h$ at $37^{\circ} \mathrm{C}$. Specific ${ }^{51} \mathrm{Cr}$-release into the supernatant as a measure of lysis was determined. To measure the effect of anti-LFA-1 on CTL activity, $\mathrm{Ll}$ or control monoclonal antibodies were introduced at the start of the $4 \mathrm{~h}$ CTL assay (1:120 final dilution). All assays were performed in triplicate.

Treatment of granulocytes with calcium ionophore, PMA, f-metleu-phe, C5a desarg, or opsonized particles. Granulocytes $\left(1 \times 10^{7} / \mathrm{ml}\right)$ were incubated for $10 \mathrm{~min}$ at $37^{\circ} \mathrm{C}$ in Krebs-lactated Ringer's buffer to which none or one of the following reagents were added: dimethyl sulfoxide $(1 \mu \mathrm{l} / \mathrm{ml})$, calcium ionophore $(1 \mu \mathrm{M})$, f-Met-Leu-Phe $(1 \mu \mathrm{M})$, PMA $(0.1 \mu \mathrm{g} / \mathrm{ml})$, and C5a desarg $(125 \mathrm{ng} / \mathrm{ml})$. Measurement of cobalamin-binding protein $(20)$ in granulocytes before and after exposure to calcium ionophore showed that this treatment decreased the cellular content of cobalamin-binding protein by $65-75 \%$ but reduced beta glucoronidase activity by only 10-15\% (data not shown). At the end of incubation, cells were washed twice in PBS, then treated with monoclonal antibodies to Mol, Mo5, LFA-1, or a negative control followed by fluorescein-labeled goat anti-mouse Ig and cell surface fluorescence analysis (5).

Human granulocytes $\left(400 \mu \mathrm{l}\right.$ of $\left.2 \times 10^{7} / \mathrm{ml}\right)$ were exposed to lipopolysaccharide-coated oil red or serum-opsonized oil red $\mathrm{O}(100$ $\mu \mathrm{l}$ ) in a total volume of $1 \mathrm{ml}$ for $10 \mathrm{~min}$ at $37^{\circ} \mathrm{C}$. Following centrifugation at $220 \mathrm{~g} \times 10 \mathrm{~min}$, the pelleted granulocytes were washed once and resuspended in $1 \mathrm{ml}$ of PBS. Granulocytes were also incubated for $60 \mathrm{~min}$ at $37^{\circ} \mathrm{C}$ with sheep erythrocyte alone or coated with anti-sheep erythrocyte IgG antibody (Cordis Corp., Miami, FL). Noningested SE were hypotonically lysed and granulocytes were washed two times in PBS at $4^{\circ} \mathrm{C}$ and processed for immunofluorescence analysis. Phagocytosis was confirmed by microscopic inspection.

Preparation and iodination of granulocyte subcellular fractions.
Granulocytes from a single donor were obtained by leukopheresis and purified on Ficol-Hypaque at $4^{\circ} \mathrm{C}$. The alpha, beta, and gamma fractions were obtained by density centrifugation on Percoll exactly as described by Borregaard et al. (21). The composition of each fraction was determined by measuring myeloperoxidase ( $\alpha$-granules) (22), cobalamin-binding protein (specific or $\beta$-granules) (20), and alkaline phosphatase (plasma membrane $[\gamma]$ ) (22). Approximately $70 \%$ of total cobalamin-binding protein was in the specific granule fraction with $15 \%$ of total present in each of the alpha and gamma fractions, respectively. The membrane (gamma) fraction contained $73 \%$ of total alkaline phosphatase activity with 17 and $10 \%$ present in the beta and alpha granule fraction, respectively. The alpha granule fraction contained $68 \%$ of the total myeloperoxidase activity, with $19 \%$ and $13 \%$ of the total present in the beta and gamma fractions, respectively (data not shown). The protein content of each fraction was measured by the method of Lowry et al. (23) using human serum albumin (Armor Pharmaceutical Co., Kankakee, IL) as standard. $50 \mu \mathrm{g}$ of each fraction were incubated for $10 \mathrm{~min}$ at $0^{\circ} \mathrm{C}$ in PBS containing phenylmethylsulfonyl fluoride (2 mM) and $0.5 \%$ Non-idet P40 (NP40), and then radiolabeled with ${ }^{125}$ I (New England Nuclear) using the chloramine T method (24). A sample from each fraction was removed for trichloracetic acid precipitation and the rest of the samples were extensively dialyzed against ice-cold PBS. Immunoprecipitation using anti-Mol monoclonal antibody was performed as described (1). The specific activity of the alpha (azurophilic granule), beta (specific granule), and gamma (plasma membrane) fractions were $3.66 \times 10^{5}, 2.10 \times 10^{5}$, and $1.60 \times 10^{5}$ $\mathrm{cpm} / \mu \mathrm{g}$, respectively.

\section{Results}

Granulocytes, monocytes, and nonadherent PBL containing both $\mathrm{T}$ and $\mathrm{B}$ lymphocytes from two patients with Mol deficiency had no detectable fluorescence when a monoclonal antibody to LFA-1 (L1) was used (Fig. 1) (Table I). L1 antibody immunoprecipitated from ${ }^{125}$ I surface-labeled normal granulocyte lysates, two noncovalently linked peptides of 177,000 and $94,000 \mathrm{D}$ (Fig. 2), similar to those immunoprecipitated from human lymphocytes and B lymphoblastoid cell lines $(2,15,18)$. Using this same antibody, no detectable radiolabeled bands were immunoprecipitated from the patient's ${ }^{125}$ I-labeled cells (Fig. 2) although ${ }^{125}$ I-labeling of surface proteins of patient's was similar to that of control cells (data not shown).

Other antigens, such as I-2 (Ia), T3, T4, and T8, were expressed normally on the patients' circulating cells (Fig. 1, Table I, and data not shown). Other monoclonal antibodies to LFA-1 (L5, L11, and TA-1) were unreactive with the patients' granulocytes and resting $T$ cells by immunofluorescence analysis suggesting that these two patients are probably deficient in the whole LFA-1 molecule rather than in a single epitope. In a similar manner, no detectable bands were immunoprecipitated from the patients' granulocytes using monoclonal antibodies to the alpha subunit of Mol and to the common beta subunit (reference 10 and data not shown).

Alloantigen, mitogen, and antigen-induced proliferation of LFA-1-deficient lymphocytes. Functionally, LFA-1 antigen appears to be involved in T lymphocyte proliferation and CTL- 


\section{FLUORESCENCE ANALYSIS}

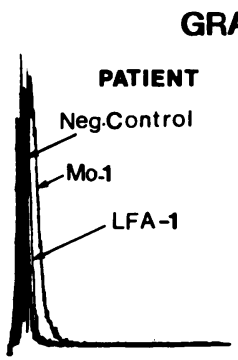

\section{GRANULOCYTES}

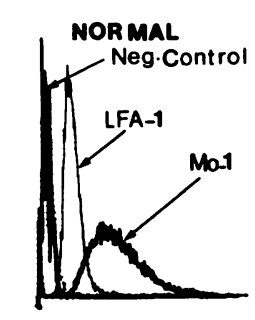

\section{LYMPHOCYTES}

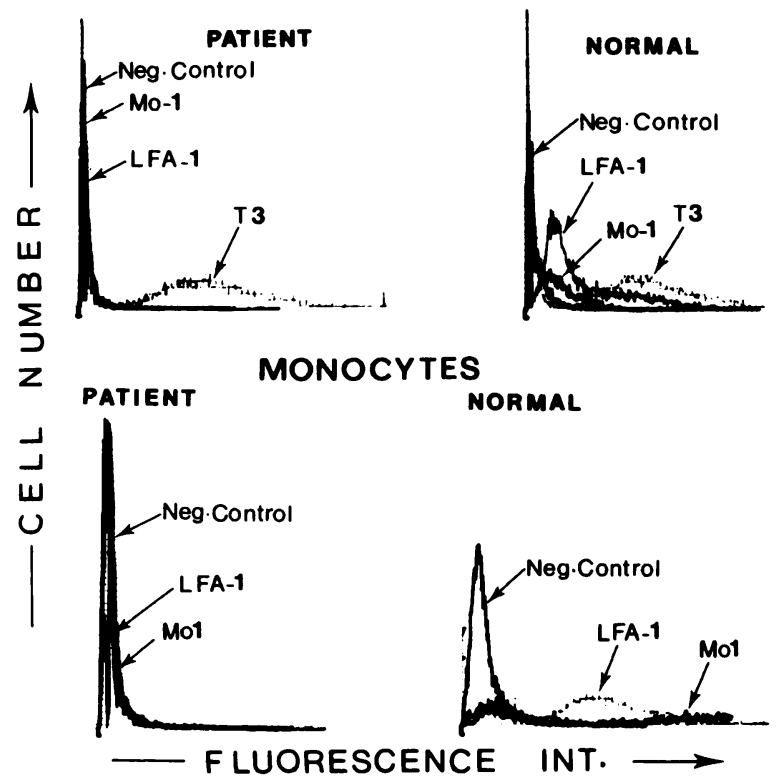

Figure 1. Immunofluorescence analysis of patient (9) and control cells using monoclonal antibodies to cell surface structures. No detectable staining on patient's granulocytes, monocytes, and PBL is noted when monoclonal antibody to LFA-1 is used. Similar analysis showed little or no staining with monoclonal antibody to Mol on the patient's granulocytes and monocytes, respectively.

mediated killing based on the ability of monoclonal antibodies to inhibit these functions on normal cells $(2,3,15)$. The effect of LFA-1 deficiency on these functions was next examined. As shown in Table II, LFA-1-deficient lymphocytes proliferated in response to alloantigenic stimuli produced by four different B cell lines as well as to TT antigen. Mitogen-induced lymphoproliferation was normal in response to Con A (6.25-62.5 $\mu \mathrm{g} / \mathrm{ml})$. PHA $(0.125-0.25 \mu \mathrm{g} / \mathrm{ml})$ induced lymphoproliferation was significantly reduced in both LFA-1-deficient patients and was more striking at the lower concentration of the lectin (Table II and data not shown). The introduction of anti-LFA1 (L1 or L5) inhibited the patient's proliferative responses to soluble antigen, lectins, and alloantigens by $20-60 \%$ (Table
Table I. Relative Surface Expression of Mo-1 and LFA-1 on Patient 2*

\begin{tabular}{|c|c|c|c|c|}
\hline \multirow[t]{2}{*}{ Cell } & \multirow[t]{2}{*}{ Individual } & \multicolumn{3}{|c|}{ Relative specific fluorescence (linear) $\neq$} \\
\hline & & LFA-I & Mo-1 & Mo-5 \\
\hline \multirow[t]{3}{*}{ Granulocyte } & Control & 100 & 100 & 100 \\
\hline & Patient & 0 & 23 & 78 \\
\hline & & LFA-1 & Mo-1 & Mo-2 \\
\hline \multirow[t]{3}{*}{ Monocyte } & Control & 100 & 100 & 100 \\
\hline & Patient & 16 & 2 & 101 \\
\hline & & LFA-1 & T3 & T4 \\
\hline \multirow[t]{2}{*}{ Lymphocyte } & Control & 100 & 100 & 100 \\
\hline & Patient & 1 & 128 & 99 \\
\hline
\end{tabular}

* This patient was described by Crowley et al. (11).

$¥$ Numbers indicate relative specific fluorescence intensity (linear scale) computed from the peak linear fluorescence channels for cells stained with each monoclonal reagent minus the peak channels of cells stained with a nonreactive control antibody. For each antigen, the fluorescence intensity of the control individual's cells has been arbitrarily assigned 100 units.

II), suggesting a partial dependence of these responses on LFA1 antigen, despite deficient cellular expression.

Cytolytic $T$ cell activity of LFA-1-deficient lymphocytes. LFA-1-deficient effector cells generated in MLR demonstrated normal CTL-mediated killing activity over a wide range of effector-to-target cell ratios (Fig. 3). Again, incubation of MLRgenerated blasts with anti-LFA-1 blocked allogeneic CTL activity by $80-90 \%$ (Fig. 3 ).

Detection of surface LFA-1 on PHA- or MLR-generated lymphoblasts from LFA-1 deficiency patients. The fact that lymphocytes from these patients were able to generate proliferative and cytotoxic responses that were partially blocked by anti-LFA-1 antibody, despite the absence of detectable quantities of LFA-1 on the surface of resting $T$ cells, was an enigma. Since these responses were mediated by "activated" $T$ cells, we examined the possibility that LFA-1 antigen may be expressed on the surface of deficient cells by mitogenic or alloantigenic stimuli. We found that PHA- or MLR-generated lymphoblasts from normal individuals increased their surface expression of LFA-1 by six-eightfold compared with unstimulated cells as determined by indirect immunofluorescence analysis (Fig. $4 A$ ). Whereas the patients' resting lymphocytes had no detectable levels of LFA-1, their PHA- or MLRgenerated blasts had detectable amounts of both the alpha and beta subunits of LFA-1 that had normal mobility on polyacrylamide gel electrophoresis (Fig. $4 A$ and $B$ ). Patients' cells, however, continued to be markedly deficient ( $\sim 5 \%$ of normal) in surface LFA-1 compared with controls (Fig. 4). 


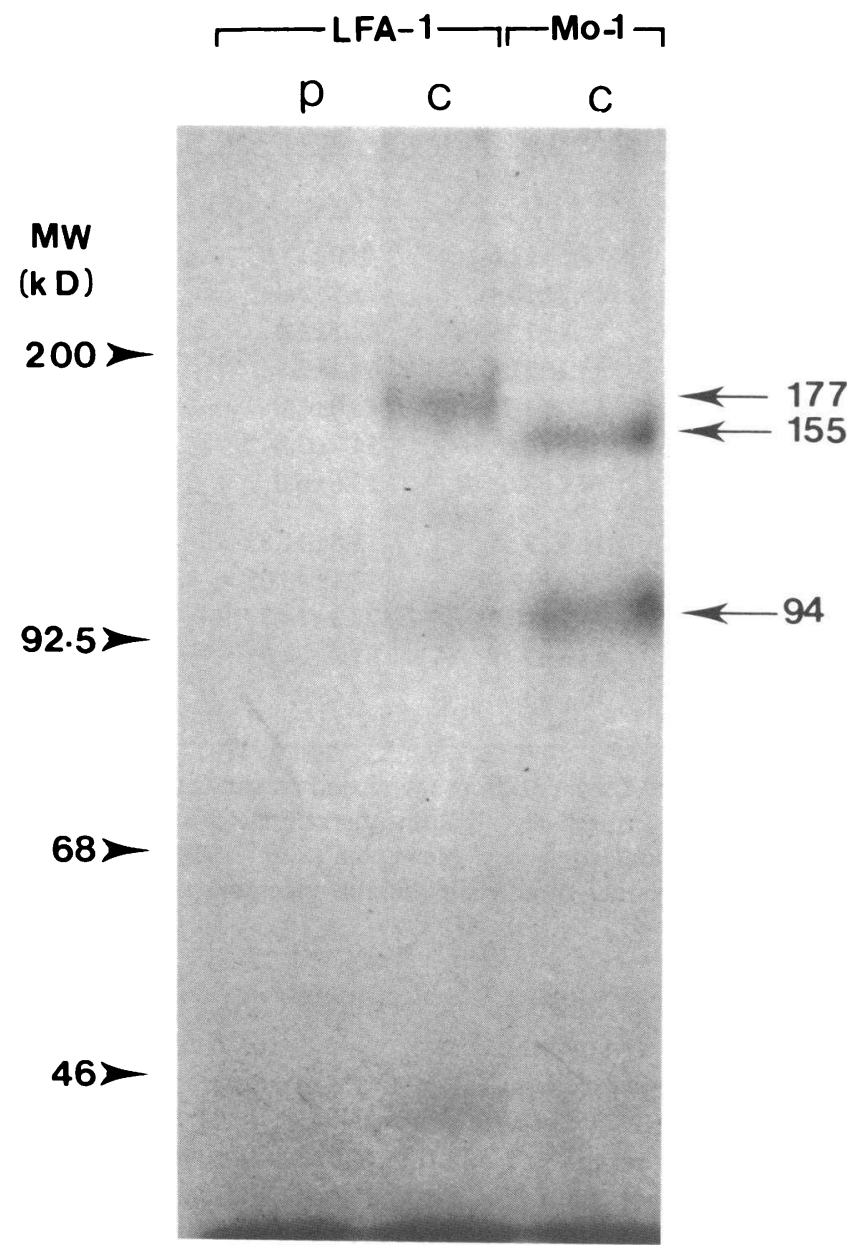

Figure 2. Radioautography of a 7\% SDS-PAGE of monoclonal immunoprecipitates from ${ }^{125} \mathrm{I}$-surface labeled granulocyte lysates. LFA-1 immuoprecipitated two radiolabeled bands of 177 and $94 \mathrm{kD}$ from control $(C)$ but not patient's $(P)$ cells. Identical results were obtained in the other patient (not shown). The alpha (155 kD) and beta ( 94 kD) subunits of $\mathrm{Mol}$ immunoprecipitated from normal granulocytes are shown for comparison. Arrow heads represent molecular weight (MW) markers.

Effect of degranulation on surface expression of $\mathrm{Mol}$ in normal granulocytes. The degree of surface expression of Mol on normal granulocytes was also crucially dependent on the state of activation of these cells. Stimuli that induced degranulation, such as calcium ionophore, PMA, C5a, and $f$-MetLeu-Phe, increased surface expression of Mol on normal granulocytes by 3-10-fold (Fig. 5). This increase in Mol surface expression was temperature-dependent (Fig. 5) and irreversible up to $1 \mathrm{~h}$ at $37^{\circ} \mathrm{C}$ (data not shown). Phagocytosis by granulocytes of $\mathrm{C} 3$ and/or IgG-opsonized particles also produced a significant increase in surface Mol expression (Fig. 5). Both the alpha and beta subunits of Mol in granulocytes were present predominantly in the specific granule fraction in addition to the plasma membrane (Fig. 6) and were expressed in a proportional manner on the plasma membrane following activation (Fig. 5, 7, and data not shown). This finding as well as the short period of incubation $\left(10 \mathrm{~min}, 37^{\circ} \mathrm{C}\right)$ and the lack of increase in Mol surface expression on the myeloid cell lines KG1 and THP-1 (data not shown), which are cells that do not have specific granules, suggest that one important mechanism leading to the significant increase in surface expression of Mol antigen in granulocytes is probably degranulation and fusion of the specific granule fraction with the plasma membrane. None of the stimuli used led to an appreciable increase in the surface expression of LFA-1 on granulocytes, suggesting that under these conditions different mechanisms may regulate the surface expression of LFA-1 on these cells (Fig. 5).

Increased Mol surface expression on granulocytes from patients with Mol deficiency and detection of a possible carrier state. Granulocytes from the two patients with Mol deficiency were next examined to determine the effect of calcium ionophore on the surface expression of Mol. As seen in Figs. 5 and 7 , calcium ionophore $(1 \mu \mathrm{M})$ produced a significant increase in Mol (but not LFA-1) surface expression on granulocytes from the two patients. Quantitation of expressed Mol sites on calcium ionophore-treated granulocytes using direct binding of ${ }^{125} \mathrm{I}-\mathrm{Fab}$ anti-Mol (1) revealed that the two patients had $4.5 \times 10^{4}$ and $4.8 \times 10^{4} \mathrm{Mol}$ sites/cell, respectively (Fig. 8), representing about a sevenfold increase over the levels measured on unstimulated cells (10). This number was still significantly less than that expressed on calcium ionophorestimulated normal cells (Fig. 8). Of special interest was the finding that calcium ionophore treatment of granulocytes from the parents of the two patients led to the detection of a carrier state which was not apparent by immunofluorescence analysis of the unstimulated cells (Table III). Direct binding assays on calcium ionophore-treated cells (Fig. 8) showed that the parents of patient one (9) but only the mother of patient two (11) were possible heterozygotes for Mol deficiency.

\section{Discussion}

Mol deficiency is a phagocyte disorder that presents clinically with recurrent bacterial infections and is associated in vitro with defective granulocyte adhesion functions (1, 9-11). In this report, we found that leukocytes from two unrelated patients with Mol deficiency were also markedly deficient in LFA-1, another leukocyte surface glycoprotein that shares a common beta subunit with Mol. On normal leukocytes, the surface expression of Mol and LFA-1 is regulated by the state of activation of the effector cell. On resting peripheral blood $T$ cells, only a small amount of LFA-1 is expressed on the plasma membrane (Fig. $4 A$ ). Upon mitogenic or alloantigenic stimulation, a marked increase in LFA-1 surface antigen is detected by immunofluorescence analysis (Fig. $4 \mathrm{~A}$ ), in agreement with the observation made on human cytolytic $T$ cell lines (2). In normal unstimulated granulocytes, a major portion 
Table II. Effect of LFA-1 Monoclonal Antibody on Proliferative Response to Allogeneic MLR, TT, and Mitogens by Patient and Control PBL

\begin{tabular}{|c|c|c|c|c|c|c|c|}
\hline \multirow[b]{2}{*}{ Stimulus } & \multirow[b]{2}{*}{ R:Sł } & \multicolumn{3}{|l|}{ Patient's PBL** } & \multicolumn{3}{|l|}{ Control PBL } \\
\hline & & $-\S$ & $+\S$ & \% Inhibition & $-\S$ & $+\S$ & \% Inhibition \\
\hline Namalva & $1: 0.5$ & $27.3 \pm 0.5^{\prime \prime}$ & $10.5 \pm 1.7$ & 62 & $79.1 \pm 12.6$ & $40.0 \pm 15.0$ & 49 \\
\hline Laz-388 & $1: 0.5$ & $54.5 \pm 3.9$ & $42.6 \pm 3.4$ & 22 & $105.7 \pm 10.4$ & $75.4 \pm 5.4$ & 29 \\
\hline Laz-388 & $1: 0.1$ & $16.8 \pm 4.8$ & $18.7 \pm 1.3$ & -11 & $71.4 \pm 2.1$ & $42.3 \pm 1.4$ & 41 \\
\hline Laz-509 & $1: 0.5$ & $63.8 \pm 7.0$ & $43.8 \pm 3.4$ & 31 & $83.4 \pm 22.4$ & $68.4 \pm 2.9$ & 18 \\
\hline Laz-509 & $1: 0.1$ & $18.7 \pm 3.2$ & $20.0 \pm 2.6$ & -7 & $62.0 \pm 3.7$ & $43.0 \pm 7.8$ & 31 \\
\hline Daudi & $1: 0.5$ & $24.7 \pm 5.0$ & $16.4 \pm 1.0$ & 34 & $88.1 \pm 4.0$ & $54.7 \pm 7.8$ & 38 \\
\hline Daudi & $1: 0.1$ & $5.9 \pm 2.5$ & $5.7 \pm 1.2$ & 3 & $38.2 \pm 3.0$ & $23.6 \pm 6.0$ & 38 \\
\hline PHA $(0.125 \mu \mathrm{g} / \mathrm{ml})$ & & $1.9 \pm 1.1$ & $0.8 \pm 0.3$ & 58 & $21.7 \pm 9.5 \pi$ & $15.8 \pm 11.8 \pi$ & 27 \\
\hline$(0.25 \mu \mathrm{g} / \mathrm{ml})$ & & $10.6 \pm 1.3$ & $3.7 \pm 0.3$ & 65 & $38.6 \pm 12.0$ ㅇ & $27.1 \pm 13.0 \pi$ & 30 \\
\hline Con A $(6.25 \mu \mathrm{g} / \mathrm{ml})$ & & $26.8 \pm 0.6$ & $9.1 \pm 0.7$ & 66 & $24.2 \pm 10.5 \pi$ & $28.2 \pm 14.3$ & -17 \\
\hline$(62.5 \mu \mathrm{g} / \mathrm{ml})$ & & $102.8 \pm 4.6$ & $85.9 \pm 10.5$ & 16 & $45.6 \pm 7.4 \pi$ & $81.8 \pm 24.0$ 의 & -79 \\
\hline TT (1:800 dilution) & & $25.1 \pm 4.7$ & $8.4 \pm 1.5$ & 67 & $16.6 \pm 3.6$ & $2.4 \pm 0.8$ & 83 \\
\hline
\end{tabular}

* Measured MLR (cpm $\times 10^{-3}$, mean \pm SD) to Laz 388, Laz 509, and Daudi (R:S ratio of 1:0.2) by PBL from the second patient (11) were 67.2 \pm 9.5 (control, 68.3 \pm 3.0 ), $57.3 \pm 4.5$ (control, 88.2 \pm 4.3 ), and $9.3 \pm 0.3$ (control, $46.7 \pm 4.3$ ), respectively. $¥$ Responder:stimulator ratio in MLR. § Proliferation obtained in the presence of anti LFA-1 (+) or a control monoclonal antibody $(-)$. "Mean $\mathrm{cpm}\left(\times 10^{-3} \pm \mathrm{SD}\right)$ among triplicate determinations from a patient or a control individual. I Mean cpm $\left(\times 10^{-3} \pm \mathrm{SD}\right)$ among mean $\left[{ }^{3} \mathrm{H}\right]$ thymidine incorporation from three control individuals (both PHA and Con A responses).

of $\mathrm{Mol}$ is located intracellularly in the specific granule fraction (Fig. 6). Recently, gelatinase-containing (cobalamin-binding protein free) granules with the same density as the specific granules were described (25). Whether some of the Mol antigen is also present in this novel granule remains to be established. Stimuli that led to degranulation such as calcium

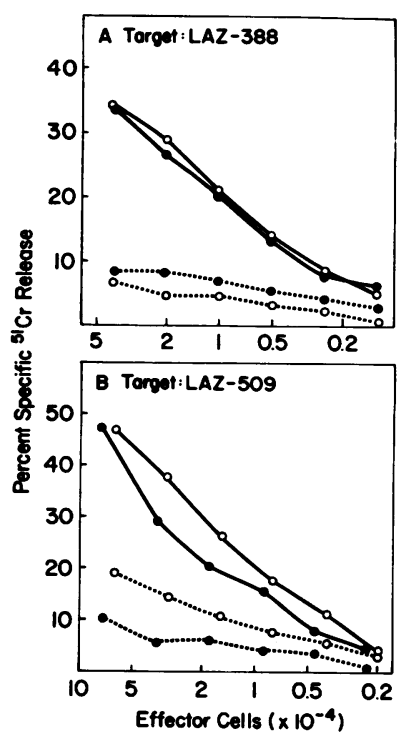

Figure 3. Effect of anti-LFA-1 monoclonal antibody on patient (9) and control CTL activity. Varying numbers of MLR-generated cytotoxic effector cells ( $\mathrm{x}$-axis) were cultured with $2 \times 10^{4}{ }^{51} \mathrm{Cr}$-labeled Laz$388(A)$ or Laz-509 $(B)$ target cells in medium containing anti-LFA-monoclonal antibody (- - -) or an isotype identical control antibody $(\stackrel{)}{\longrightarrow}$ for $4 \mathrm{~h}$ at $37^{\circ} \mathrm{C}$. Specific ${ }^{51} \mathrm{Cr}$-release (y-axis) as a measure of target cell lysis was determined.

Closed symbols (•) and open symbols (O) indicate the mean specific ${ }^{31} \mathrm{Cr}$-release performed by patient and control effector cells, respectively. Similar results were obtained using lymphocytes from the other patient (11) (data not shown). inophore $\mathrm{A} 23187$, chemotactic peptides ( $f$-Met-Leu-Phe or C5a), PMA, or phagocytosis produced a 3- to 10-fold increase in Mol surface expression. There was no comparable increase in LFA-1 surface expression although both Mol and LFA-1 may share the same beta subunit (8). Translocation of the Mol heterodimer from the specific granule fraction to the plasma membrane probably mediates the increase in Mol surface expression on granulocytes. The mechanism leading to an increase in surface LFA-1 on lymphocytes is unclear but may involve neosynthesis. In addition to Mol, three other granulocyte antigens, the $\mathrm{C} 3 \mathrm{~b}$ receptor, $f$-Met-Leu-Phe receptor, and cytochrome $b$ significantly increase on the surface upon stimulation $(21,26,27)$. These findings suggest a common mechanism whereby granulocytes store a large proportion of functionally active molecules intracellularly and translocate them to the plasma membrane upon activation.

LFA-1-deficient resting $T$ cells proliferated in response to a variety of stimuli such as antigen, mitogen, and alloantigens (Table II). They also had normal T cell-mediated cytolysis of two different B cell targets and natural killing of K562 target cells (Fig. 3) (10). The partial or more complete inhibition by LFA- 1 monoclonal antibodies in both patient and control cells suggested the involvement of LFA- 1 antigen in these responses (Table II and Fig. 3). Whereas no detectable LFA-1 was seen on granulocytes or resting $T$ cells (Figs. 1 and 2, Table I), PHA- or MLR-activated lymphoblasts from these patients expressed detectable amounts of LFA-1 on the cell surface (Fig. $4 \mathrm{~A}$ ). Moreover, this antigen had normal mobility as determined by immunoprecipitation and sodium dodecyl sul- 

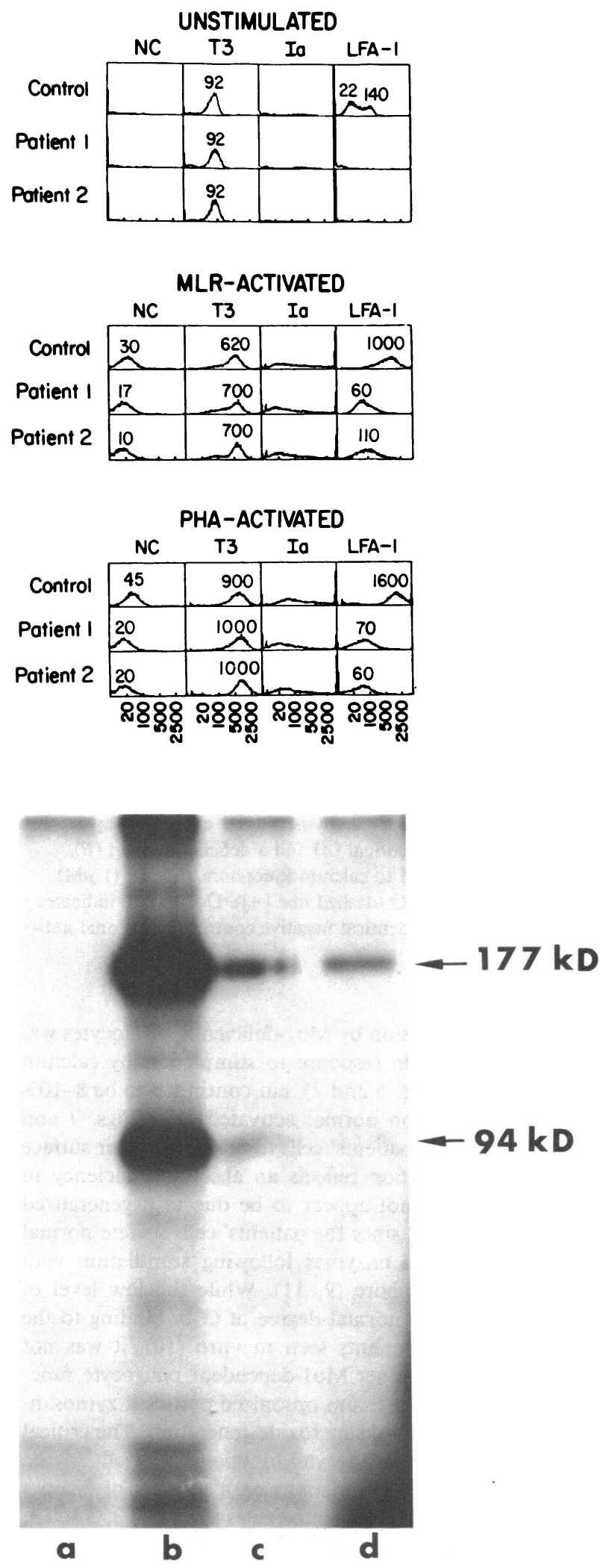

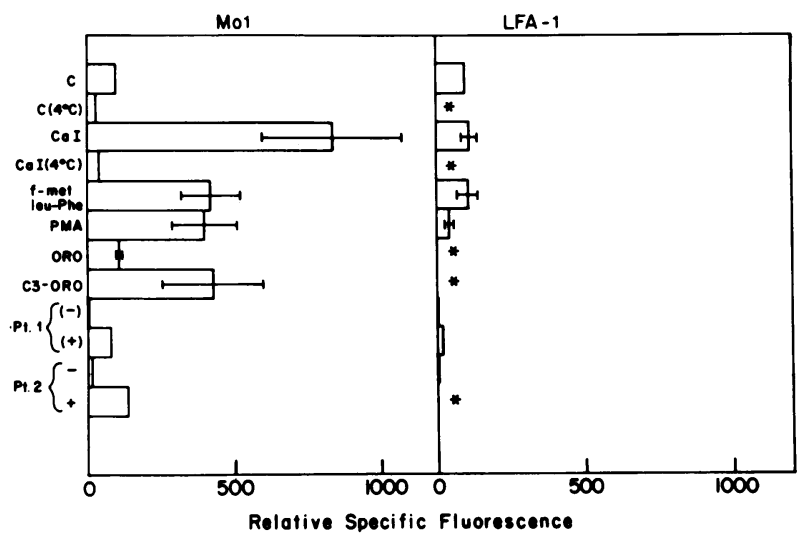

Figure 5. Surface membrane expression of Mol and LFA-1 after treatment of normal or deficient granulocytes with calcium ionophore, CaI, PMA, $f$-Met-Leu-Phe, or exposure to phagocytic stimuli. The fluorescence intensity of the control individual's unstimulated cells has been arbitrarily assigned 100 units. Values represent mean $\pm \mathrm{SD}$ from two to six experiments. The concentration of $\mathrm{CaI}, f$ met-leu-phe, and C5a desarg produced half maximal surface expression of Mol at $5 \times 10^{-8} \mathrm{M}, 1 \times 10^{-9} \mathrm{M}$, and $20 \mathrm{ng} / \mathrm{ml}$, respectively (data not shown). Ingestion of IgG-coated sheep erythrocytes was associated with a fourfold increase in Mol surface expression compared with untreated or sheep erythrocyte-treated granulocytes (not shown). $(-)$ and $(+)$ refer to unstimulated or calcium ionophore (CaI)-treated granulocytes, respectively, from patient 1 (Reference 9) or patient 2 (Reference 11$){ }^{*}$, not done.

fate-polyacrylamide gel electrophoresis analysis (Fig. $4 \mathrm{~B}$ ). The amount of LFA-1 that was expressed on the surface of PHAor MLR-generated lymphoblasts continued to be markedly reduced ( $\sim 5 \%$ of normal) compared with normal cells (Fig. 4 $A$ ). The abnormally low lymphoproliferative response to PHA shown by these two patients may be a manifestation of this degree of LFA-1 deficiency (Table II). This abnormality was more apparent at lower concentrations of the mitogen (Table II), a finding which is similar to that reported recently in a

Figure 4. (A) Immunofluorescence analysis of LFA-1 expression relative to $\mathrm{T} 3$ and Ia by lymphocytes from the two patients and a control individual before and after PHA or alloantigenic (MLR) stimulation. Detectable amounts of LFA-1 were seen on stimulated (Ia positive) but not unstimulated lymphocytes from these two patients. Despite equal amounts of the T3 marker, LFA-1 expression by MLR- and PHA-activated lymphoblasts from both patients remains significantly deficient relative to control lymphoblasts. NC indicates the binding of a non-reactive control monoclonal antibody. Numbers on the X-axis and within each histogram indicate peak linear fluorescence channels. $(B)$ A radioautograph of a 7.5\% SDS-PAGE of LFA1 immunoprecipitated from ${ }^{125}$ I-surface labeled PHA-generated blasts from the control (lane $b$ ) and patients (lanes $c$ and $d$ ). Lane (a) shows immunoprecipitation with a nonreactive monoclonal from ${ }^{125}$ I-control cells. ${ }^{125}$ I-incorporation into cell proteins from patients or control was similar (not shown). 


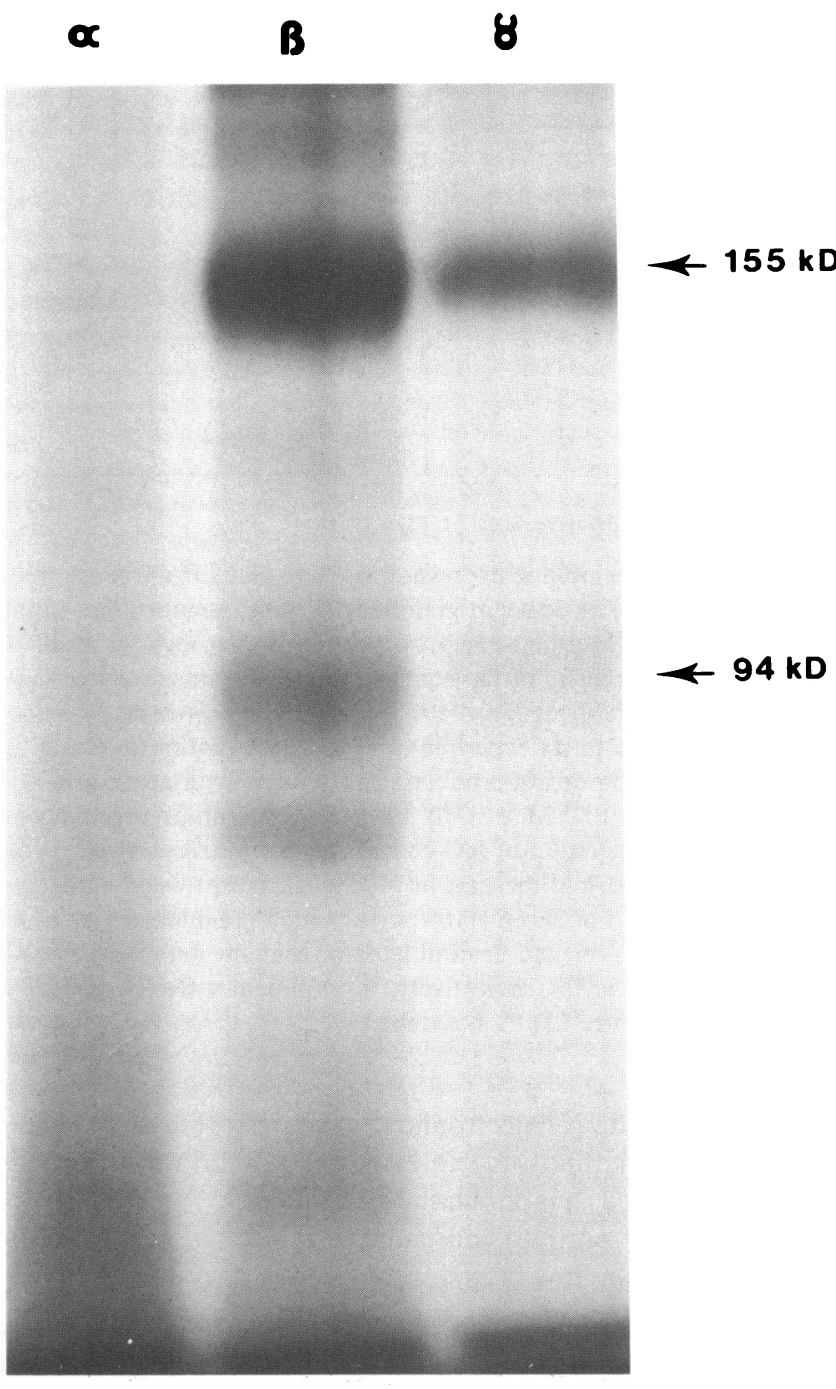

Figure 6. Radioautograph of a 9\% SDS-PAGE of Mol immunoprecipitated from ${ }^{125}$ I-labeled granulocyte subcellular fractions: alpha (primary granules), beta (specific granules), or gamma (plasma membrane). In addition to Mol, two unidentified bands of apparent molecular weights 185 and $78 \mathrm{kD}$ were seen only in the beta fraction. Mol was primarily detected in the plasma membrane and specific granule fractions but not in the primary granules.

third patient with recurrent bacterial infections (28). The dependence of lymphoproliferation on the lectin concentration may also explain in part the differences seen in the ConAinduced response in our patient and that of Beatty et al. (28). While the inhibitory effect of anti-LFA-1 monoclonal antibodies suggest an involvement of LFA-1 in these $T$ cell responses, LFA-1 deficiency may in part be compensated for by the normal expression of other functionally related molecules such as T3, T4, and T8 (29).

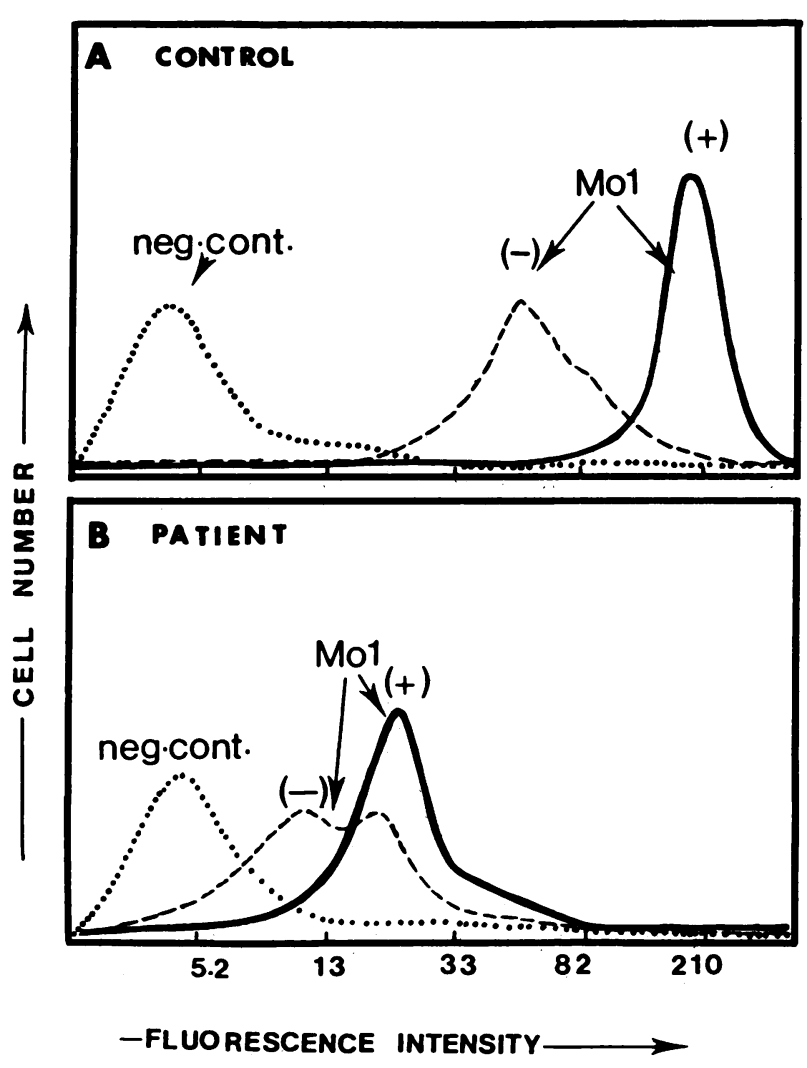

Figure 7. Immunofluorescence analysis of Mol expression by granulocytes from a normal individual $(A)$ and a deficient patient $(B)$. Granulocytes were exposed to calcium ionophore A23189 $(1 \mu \mathrm{M})$ (solid line [+]) or to DMSO (dashed line [-]). Dotted line indicates the binding of a subclass identical negative control monoclonal antibody.

Surface Mol expression by Mol-deficient granulocytes wa significantly increased in response to stimulation by calcium ionophore A23187 (Figs. 5 and 7), but continued to be 8-10\% of the levels detected on normal activated cells (Figs. 7 and 8). The inability of the patients' cells to normalize their surface Mol following stimulation reflects an absolute deficiency in this antigen and does not appear to be due to a generalized defect in degranulation, since the patients' cells secrete normal amounts of lyosozymal enzymes following stimulation with PMA or calcium ionophore $(9,11)$. While the low level of Mol might explain the normal degree of $\mathrm{C} 3 \mathrm{bi}$ binding to the granulocytes of these patients seen in vitro (10), it was not sufficient to normalize other Mol-dependent phagocyte functions such as ingestion of serum opsonized particles, zymosaninduced degranulation, and superoxide generation. The critical role of Mol in these phagocyte functions as well as the dependence of lymphocyte functions on a number of distinct but functionally related surface molecules such as T3, T4, T8, and LFA-1 may be one reason for the predominance of 


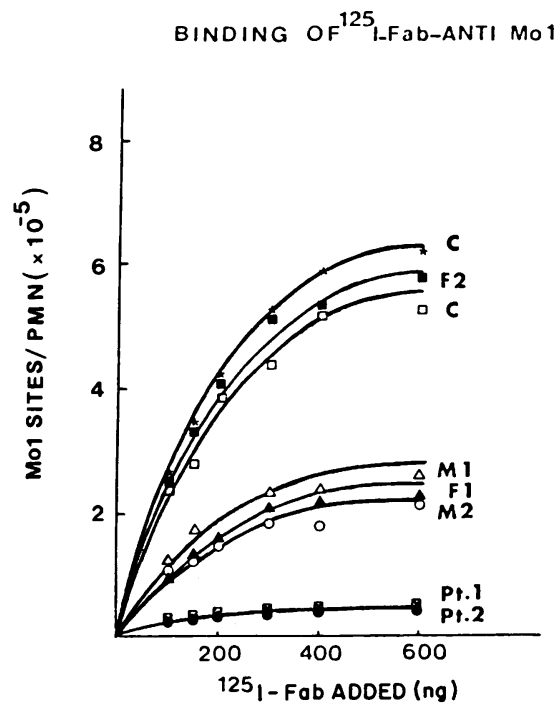

Figure 8. Binding of ${ }^{125} \mathrm{I}$-labeled Fab anti-Mol monoclonal antibody to granulocytes from two normal individuals $(C)$, a patient with Mol deficiency $(\mathrm{Pl})(9)$, his father $(\mathrm{Fl})$ and mother $(\mathrm{Ml})$, as well as the other patient described by Crowley et al. (11) (Pt2) and his parents (M2 and F2). Binding was done on granulocytes pretreated with calcium ionophore $(1 \mu \mathrm{M})$. In all cases, half maximal saturation occurred at $1.1-1.2 \mu \mathrm{g} / \mathrm{ml}$, indicating that the monoclonal antibody binds with equal affinity to Mol on patients, their parents and controls. Calcium ionophore-stimulated granulocytes from seven normal individuals (including the two shown in this figure) had $5.6 \pm 0.75$ $\times 10^{5}$ (mean \pm SD) Mol binding sites/cell.

bacterial infections in these two patients with this combined immunodeficiency disorder.

Quantitation of Mol expressed on the surface of calcium ionophore A23187-treated cells from the parents of these two patients showed that granulocytes from the parents of one patient but only the mother of the other patient had significantly reduced numbers ( $\sim 50 \%)$ of Mol binding sites compared with normal cells (Fig. 8). This finding may suggest $(a)$ an inability of these granulocytes to fully express their normal content of Mol upon optimal activation, or (b) that these cells have $\sim 50 \%$ of the normal total cellular content of this antigen. Previous studies $(9,11)$ showed that granulocytes from these patients had a normal secretory response suggesting that the differences noted in Mol surface expression are not a reflection of a degranulation defect. In favor of the second possibility is previous data showing that these same individuals had $\sim 50 \%$ of the normal total granulocyte content of "gp 150" as determined by densitometric scanning of the total cell lysate $(9,11)$. Therefore, these studies suggest a heterogeneity in the inheritance of Mol deficiency in humans. They also point out the importance of standardizing the state of activation of effector cells in future studies aimed towards phenotyping relatives of these patients and understanding the molecular basis of this newly recognized disorder.
Table III. Relative Surface Membrane Expression of Mo-1 and LFA-1 on Myeloid Cells From Two Patients with Mo-1 Deficiency Relative to Controls and Family Members

\begin{tabular}{lllrrr}
\hline & & & \multicolumn{3}{c}{\begin{tabular}{l} 
Relative specific fluorescence \\
\cline { 3 - 5 } (linear)
\end{tabular}} \\
\cline { 3 - 6 } Cell & Family & Individual & Mo-1 & Mo-5 & LFA-1 \\
\hline Granulocyte & \multirow{2}{*}{ Family 1 } & (Control) & 100 & 100 & 100 \\
& & Patient & 12 & 96 & 14 \\
& & Mother & 84 & 115 & 95 \\
& & Father & 73 & 85 & 86 \\
Granulocyte & Family 2 & (Control) & 100 & 100 & 100 \\
& & Patient & 23 & 78 & 0 \\
& & Mother & 99 & 106 & 124 \\
& & Father & 122 & 125 & 106 \\
\hline
\end{tabular}

* Numbers indicate relative specific fluorescence intensity (linear scale) computed from the peak linear fluorescence channels for cells stained with each monoclonal reagent minus the peak channels of cells stained with a nonreactive control antibody. For each antigen, the fluorescence intensity of the control individual's cells has been arbitrarily assigned 100 units.

\section{Acknowledgments}

We are indebted to Dr. Harvey R. Colten for his help and critical review of the manuscript, Dr. Fred S. Rosen for his help and support, and Dr. Bernard M. Babior for allowing us to study his patient. We thank Ms. Maria Desy and Ms. Janis Roach for their expert technical assistance and Ms. Helen Hourihan for her secretarial help.

This work was supported by U. S. Public Health Service grants AI17452, HL22487, CA33555, and RR02172.

\section{References}

1. Arnaout, M. A., R. F. Todd III, N. Dana, J. Melamed, S. F. Schlossman, and H. R. Colten. 1983. Inhibition of phagocytosis of complement $\mathrm{C} 3$ or immunoglobulin G-coated particles and of C3bi binding by monoclonal antibodies to a monocyte-granulocyte membrane glycoprotein (Mol). J. Clin. Invest. 72:171-179.

2. Ware, C. F., F. Sanchez-Madrid, A. M. Krensky, S. J. Burakoff, J. L. Strominger, and T. A. Springer. 1983. Human lymphocyte function associated antigen-1 (LFA-1): identification of multiple antigenic epitopes and their relationship to CTL-mediated cytotoxicity. $J$. Immunol. 131:1182-1188.

3. Davignon, D., E. Martz, T. Reynolds, K. Kurzinger, and T. A. Springer. 1981. Monoclonal antibody to a novel lymphocyte functionassociated antigen (LFA-1): mechanism of blocking of $T$ lymphocytemediated killing and effects on other $\mathrm{T}$ and $\mathrm{B}$ lymphocyte functions. J. Immunol. 127:590-595.

4. Todd, R. F., III, A. van Agthovan, S. F. Schlossman, and C. Terhorst. 1982. Structural analysis of differentiation antigen Mol and Mo2 on human monocytes. Hybridoma. 1:329-337.

5. Todd, R. F., III, and S. F. Schlossman. 1982. Analysis of antigenic determinants on human monocytes and macrophages. Blood. 59:775-786. 
6. Todd, R. F., III, A. K. Bhan, S. E. Kabawat, and S. F. Schlossman. 1984. Human myelomonocytic differentiation antigen defined by monoclonal antibodies. In Leukocyte Typing. B. A. Bounswell, J. Dausset, C. Milstein, and S. F. Schlossman, editors. SpringerVerlag, New York. 424-433.

7. Kurzinger, K., M. Ho, and T. A. Springer. 1982. Structural homology of a macrophage differentiation antigen and an antigen involved in T cell mediated killing. Nature (Lond.). 296:668-670.

8. Sanchez-Madrid, F., J. A. Nagy, E. Robbins, P. Simon, and T. A. Springer. 1983. A human leukocyte differentiation family with distinct $\alpha$ subunits and a common $\beta$ subunit: the lymphocyte functionassociated antigen (LFA-1), the C3bi complement receptor (OKM1/ Mac1), and the p150, 95 molecule. J. Exp. Med. 158:1785-1803.

9. Arnaout, M. A., J. Pitt, H. J. Cohen, J. Melamed, F. S. Rosen, and H. R. Colten. 1982. Deficiency of a granulocyte membrane glycoprotein (gp150) in a boy with recurrent bacterial infections. $N$. Engl. J. Med. 306:693-699.

10. Dana, N., R. F. Todd, J. Pitt, T. A. Springer, and M. A. Arnaout. 1984. Deficiency of a surface membrane glycoprotein (Mol) in man. J. Clin. Invest. 73:153-159.

11. Crowley, C. A., J. T. Curnutte, R. E. Rosin, J. Andre-Schwartz, J. I. Gallin, M. Klempner, R. Snyderman, S. S. Southwick, T. P. Stossel, and B. M. Babior. 1980. An inherited abnormality in neutrophil adhesion; its genetic transmission and its association with a missing protein. N. Engl. J. Med. 302:1163-1168.

12. Todd, R. F., III, M. A. Arnaout, R. E. Rosin, C. A. Crowley, W. A. Peters, and B. M. Babior. 1984. Subcellular localization of the large subunit of Mol (Mol $\alpha$; formerly, gp 110), a surface glycoprotein associated with neutrophil adhesion. J. Clin. Invest. 74:1280-1290.

13. Boyum, A. 1968. Isolation of mononuclear cells and granulocytes from human blood. Scand. J. Clin. Lab. Invest. 97(Suppl.):77-89.

14. Pertoft, H., A. Johnsson, B. Wamegard, and R. Seljelid. 1980. Separation of human monocytes on density gradients of percoll. $J$. Immunol. Methods. 33:221-229.

15. Spits, H. 1983. The induction and characterization of human cytotoxic T cell clones. Ph.D. thesis. Department of Immunology of the Antoni van Leeuwenhoekhuis, The Netherlands Cancer Institute, University of Amsterdam. Rodopi, Amsterdam. 103-121.

16. Nadler, L. M., P. Stashenko, R. Hardy, J. Pesando, E. J. Yunis, and S. F. Schlossman. 1981. Monoclonal antibodies defining serologically distinct HLA-D/DR related la-like antigens in man. Hum. Immunol. 1:77-90.

17. Reinherz, E. L., S. Meuer, K. A. Fitzgerald, R. E. Hussey, H. Levine, and S. F. Schlossman. 1982. Antigen recognition by human T lymphocytes is linked to surface expression of the T3 molecular complex. Cell. 30:735-743.

18. Lebien, T. W., J. G. Bradley, and B. Koller. 1983. Preliminary structural characterization of the leukocyte cell surface molecule recognized by monoclonal antibody TA-1. J. Immunol. 130:1833-1836.

19. Muirhead, K. A., T. C. Schmitt, and A. R. Muirhead. 1983. Determination of linear fluorescence intensity from flow cytometric data accumulated with logarithmic amplifiers. Cytometry. 3:251-256.

20. Gottlieb, C., K. S. Lau, L. R. Wasserman, and V. Herbert. 1965. Rapid charcoal assay for intrinsic factor (IF), gastric juice unsaturated B12 binding capacity, antibody to IF, and serum unsaturated B12 binding capacity. Blood. 25:875-884.

21. Borregaard, N., J. M. Heiple, E. R. Simons, and R. A. Clark. 1983. Subcellular localization of the b-cytochrome component of the human neutrophil microbicidal oxidase: translocation during activation. J. Cell Biol. 97:52-61.

22. Bretz, U., and M. Baggiolini. 1974. Biochemical and morphological characterization of azurophil and specific granules of human neutrophilic polymorphonuclear leukocytes. J. Cell Biol. 63:251-269.

23. Lowry, O. H., N. J. Rosebrough, A. L. Farr, and R. J. Randall. 1951. Protein measurement with the folin phenol reagent. J. Biol. Chem. 193:875-893.

24. Sonada, S., and M. Schlamowitz. 1970. Studies of ${ }^{125}$ I trace labelling of immunoglobulin $\mathrm{G}$ by chloramine T. Immunochemistry. 7:885-898.

25. Dewald, B., V. Bretz, and M. Baggiolini. 1982. Release of gelatinase from a novel secretory compartment of human neutrophils. J. Clin. Invest. 70:518-525.

26. Fletcher, M. P., B. E. Seligmann, and J. I. Gallin. 1982. Correlation of human neutrophil secretion, chemoattractant receptor mobilization and enhanced functional capacity. J. Immunol. 128:941948.

27. Fearon, D. T., and L. A. Collins. 1983. Increased expression of $\mathrm{C} 3 \mathrm{~b}$ receptors on polymorphonuclear leukocytes induced by chemotactic factors and by purification procedures. J. Immunol. 130:370375.

28. Beatty, P. G., J. M. Harlan, H. Rosen, J. A. Hansen, H. D. Ochs, T. H. Price, R. F. Taylor, and S. J. Klebanoff. 1984. Absence of monoclonal-antibody-defined protein complex in boy with abnormal leukocyte function. Lancet. I:535-537.

29. Reinherz, E. L., S. C. Meuer, and S. F. Schlossman. 1983. The delineation of antigen receptors on human T lymphocytes. Immunol. Today. 4:5-8. 